
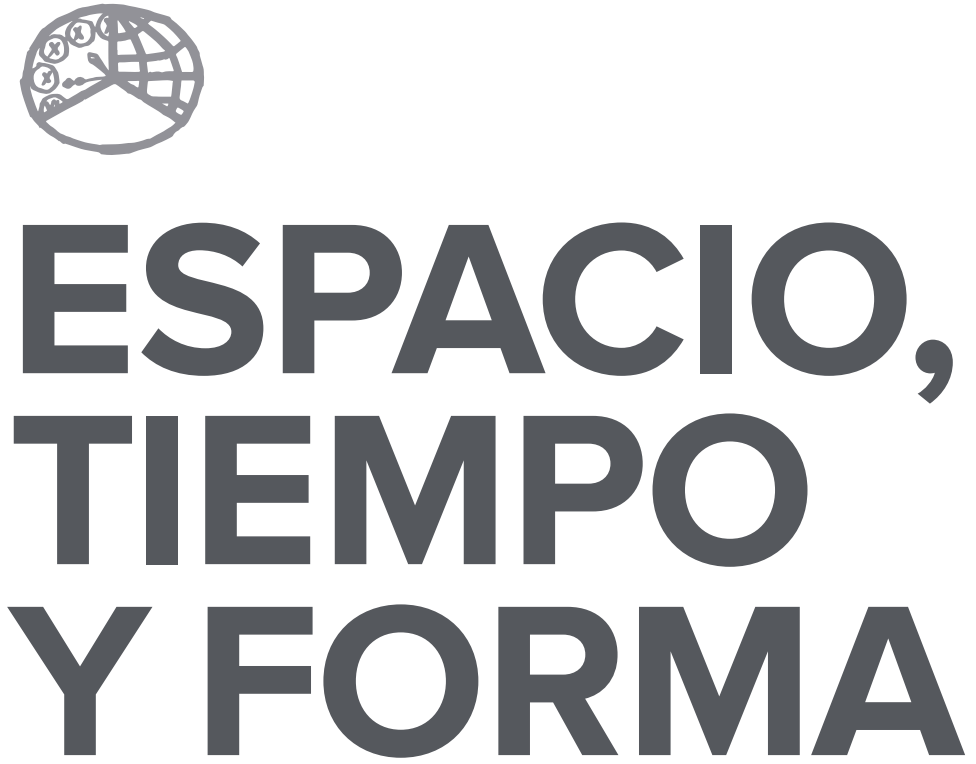

AÑO 2018

ISSN 0214-9745

E-ISSN 2340-1362

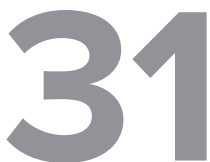

SERIE III HISTORIA MEDIEVAL

REVISTA DE LA FACULTAD DE GEOGRAFÍA E HISTORIA 



\section{ARTÍCULOS · ARTICLES}





\title{
LA ORDEN DE CALATRAVA EN LA \\ BAJA EDAD MEDIA (1350-1500): \\ REPASO HISTORIOGRÁFICO
}

\section{THE MILITARY ORDER OF CALATRAVA IN THE LATE MIDDLE AGES (1350-1500): REVIEW OF SCHOLARSHIP}

\author{
Milagros Plaza Pedroche ${ }^{1}$
}

Recepción: 2017/02/01 - Comunicación de observaciones de evaluadores: 2017/7/19 .

Aceptación: 2017/07/27

DOI: http://dx.doi.org/10.5944/etfiii.31.2018.18195

\section{Resumen ${ }^{2}$}

En el presente artículo se concede atención al desarrollo de la producción historiográfica referente a la Orden de Calatrava en el ámbito castellanoleonés y en el periodo comprendido entre I350 y I500. En él se realiza un balance que permite conocer los vacíos informativos que todavía perviven dentro de este campo y las líneas de investigación que de cara al futuro se abren a los medievalistas.

\section{Palabras clave}

Orden de Calatrava; Castilla; Historiografía; líneas de investigación; vacíos informativos.

\section{Abstract}

The present study focuses on the developments of the scholarship on the Military Order of Calatrava in the kingdom of Castile and Leon in the period between 1350 and I500. It provides an assessment of current research which will identify the gaps of information that still persist within this field of study and the research strategies that these may provide to medievalists in the future.

1. Universidad de Castilla-La Mancha. C.e.: milagros.ppedroche@uclm.es

2. Este trabajo ha sido desarrollado en el marco de mi proyecto de tesis doctoral financiado por el Ministerio de Educación, Cultura y Deporte mediante una beca para la Formación del Profesorado Universitario. Referencia de la ayuda: FPU15/04774. 


\section{Keywords}

The Military Order of Calatrava; Castile; Historiography; Research Strategy; Information Gaps.

\section{INTRODUCCIÓN}

Las órdenes militares constituyen un tema de estudio clásico dentro de la historiografía. Y es que no cabe duda de que estas conforman una línea de investigación muy pertinente para conocer la sociedad medieval entre los siglos XII y XV; dado que proyectan un ideal religioso-militar identificado con una cristiandad latina en expansión y representan agentes señoriales muy característicos.

Este seguimiento ha dotado de un gran impulso su estudio y la publicación de numerosas obras vinculadas con la temática; de manera que la investigación sobre estas instituciones ha progresado sólida y sistemáticamente. Además, desde hace ya algún tiempo, los especialistas se vienen preocupando por conocer el panorama historiográfico existente en torno a ellas. Dentro de esta línea podemos citar varios repertorios comentados, de excelente calidad, como el de Derek W. Lomax, el de Philippe Josserand y el de Ladero Quesada (8I, 7I, 80). Igualmente resulta obligado mencionar otros cuatro artículos elaborados por Carlos de Ayala y sus colaboradores, y las esclarecedoras páginas que el profesor Francisco Ruiz ha dedicado a estas cuestiones (23, 31, 34, I23).

El presente trabajo se mueve en la línea de estas últimas publicaciones, es decir, está destinado a analizar cuestiones historiográficas y metodológicas. No obstante, con él no se pretende hacer un repaso de las aportaciones realizadas sobre la totalidad de las milicias hispánicas; sino que solo se concede atención al desarrollo de la producción bibliográfica referente a la Orden de Calatrava en el ámbito castellano-leonés y en el periodo comprendido entre 1350 y I50033. Nuestra intención es reflexionar sobre ella y ofrecer un balance que permita conocer los vacíos informativos que todavía perviven dentro de este campo y las líneas de investigación que de cara al futuro se abren a los jóvenes medievalistas.

3. Es necesario mencionar aquí la publicación, hace ya algunos años, de un trabajo interesado en el desarrollo historiográfico de Calatrava durante la Edad Media: RodRíguez-PICAVEA MATILLA, Enrique: «Catorce años de historiografía sobre la Orden de Calatrava en la Edad Media (1976-1989)». Hispania, 50, 175 (1990), pp. 941-964. 


\section{EL DESARROLLO DE LA HISTORIOGRAFİA SOBRE LA ORDEN DE CALATRAVA EN LAS ÚLTIMAS CENTURIAS DEL MEDIEVO (1350-1500)}

Suele situarse el punto de partida dentro del estudio de estos organismos en los años sesenta del siglo XX; ya que es entonces cuando comienzan a publicarse monografías basadas en fuentes documentales inéditas y con nuevos enfoques, de la mano de autores como E. Benito Ruano, J. O'Callaghan y D.W. Lomax ${ }^{4}$. Para Ladero Quesada estas son obras de muy distinto calado, pero evidencian la consolidación de una nueva tendencia que consiste en dotar de mayor protagonismo a las fuentes, frente a ciertas corrientes anteriores de carácter más literario y apologético5. De esta manera se ha conseguido cubrir algunos vacíos informativos existentes en torno al último tercio del siglo XIII y todo el XIV, periodos sustancialmente menos estudiados dentro de la evolución medieval de las órdenes.

Para el profesor Carlos de Ayala, en las últimas dos décadas, la historiografía dedicada a estas instituciones religioso-guerreras ha alcanzado el suficiente grado de madurez como para poder ser considerada como una especialidad con personalidad propia dentro del ámbito del medievalismo. Encuentra pruebas de ello en el hecho de que en diferentes universidades haya equipos de investigadores especializados en la temática, tales como la Universidad Autónoma de Madrid y la Universidad de Castilla-La Mancha; así como en la aparición de revistas científicas centradas en la materia ${ }^{6}$.

Otro indicio de madurez sería la creciente celebración de congresos y encuentros científicos. Aquí debemos recalcar que ha sido en tierras castellano-manchegas donde se ha llevado a cabo la celebración de los congresos científicos de ámbito peninsular más importantes dedicados a estos organismos7. Bajo los títulos Las Órdenes Militares en la Península Ibérica y Las Órdenes Militares y la construcción de la sociedad occidental, las reuniones se celebraron en Ciudad Real en I996 y 2015 respectivamente, gracias al esfuerzo realizado por el Departamento de Historia de la Universidad de Castilla-La Mancha ${ }^{8}$.

4. Benito Ruano, Eloy: «Las Órdenes Militares españolas y la idea de Cruzada». Hispania, 16 (1956), pp. 3-15; Lomax, Derek: La Orden de Santiago (1170-1275). Madrid, CSIC, 1965; O' CALLAGHAN, Joseph: «The affiliation of the Order of Calatrava with the Order of Citeaux». Analecta Sacri Ordinis Cisterciensis, 15 (1959), pp. 161-193; 16 (1960), pp. 3-59 y 255-292.

5. LADERO QUESADA, Miguel Ángel: «La investigación sobre Órdenes Militares en la Edad Media hispánica durante los últimos decenios: Corona de Castilla y León» en IzQUIERDo BeNITO, Ricardo y RuIz Gómez, Francisco (coords.): Las Órdenes Militares en la Edad Media. Volumen I. Cuenca, Universidad de Castilla-La Mancha, 2000, pp. 10-11.

6. Hablamos concretamente de la Militarium Ordinum Analecta, nacida en Portugal a la altura de 1997 y de la Revista de las Órdenes Militares, editada en 2001 por el Real Consejo de las Órdenes Militares.

7. Ayala Martínez, Carlos de y Barquero Goñı, Carlos: «Historiografía hispánica y Órdenes Militares en la Edad Media, 1993-2003». Medievalismo: Boletín de la Sociedad Española de Estudios Medievales, 12 (2003), pp. 102-104.

8. Estos congresos vinieron acompañados de dos publicaciones: IzQUIERDO BENITO, Ricardo y RuIz GómEZ, Francisco (coords.): Las Órdenes Militares en la Edad Media. Volumen l y López SALAzAR PÉrez, J. (coord.): Las Órdenes Militares en la Edad Moderna. volumen II. Cuenca, Universidad de Castilla-La Mancha, 2000. TorRes JIMÉnez, Raquel y Ruiz Gómez, Francisco (coords.): Órdenes militares y construcción de la sociedad occidental. Cultura, religiosidad y desarrollo social de los espacios de frontera (siglos XII-XV). Madrid, Sílex, 2016. 
Sin embargo, pese al gran interés que este tema tiene para la historiografía, no han sido muchos los especialistas que hasta el momento han estudiado el desarrollo de la milicia calatrava a lo largo de toda la Edad Media; y en especial en lo que al Bajo Medievo se refiere. Como ya hemos mencionado, la atención que se ha prestado a su evolución es visiblemente desigual y la mayor parte de las investigaciones se han orientado hacia sus primeros siglos de existencia (entre ellas es obligado mencionar la prolífica obra del desgraciadamente malogrado Enrique Rodríguez-Picavea), quedando las centurias bajomedievales relegadas a un segundo plano. Las únicas excepciones que hemos encontrado a esta constante las constituyen las tesis doctorales de la norteamericana Clara R. Estow (60) y la profesora Emma Solano (I3I); publicadas ambas en la década de I970.

\subsection{DISTRIBUCIÓN GEOGRÁFICA: EL GOBIERNO Y LA ADMINISTRACIÓN DEL PATRIMONIO CALATRAVO}

Actualmente, los estudios dedicados a las encomiendas y demás propiedades calatravas entre $\mathrm{I} 350$ y 1500 son relativamente numerosos y cubren, aunque no por igual, buena parte de los territorios del antiguo reino de Castilla. Disponemos de interesantes investigaciones sobre algunas de ellas, como las que Ballesteros San José y Solano Ruiz elaboraron sobre Almoguera y Zorita (35) y el convento de San Salvador de Pinilla (132), respectivamente; o esas otras de Fernández Izquierdo acerca de Vállaga y las tierras de Guadalajara (62, 63). A Solano Ruiz debemos, además, una completa monografía sobre la materia (I3I) y dos artículos: uno con carácter general que abarca los dominios de la entidad en Andalucía durante la transición a la Modernidad y otro sobre la fortaleza de Porcuna (I30, I33).

De igual forma, Rodríguez-Picavea ha realizado aportaciones dentro de este campo, una referente al señorío de Alcaudete y otra a Calatrava la Vieja, apoyándose en su importante obra dedicada a los señoríos calatravos en Castilla durante los siglos XIl y XIII ${ }^{9}$ (I09, III). A estos se sumarían, por un lado, la monografía de Ciudad Ruiz sobre el dominio señorial y eclesiástico calatravo (53) y, por otro, tres trabajos que ofrecen una visión conjunta de los dominios que poseyeron las instituciones de esta naturaleza en Castilla a fines de la época medieval, el de Ladero Quesada, el de Rodríguez Molina y el de Segura Graíño y Torreblanca (79, Io6, I29).

En otro orden de cosas, pero en relación directa con la temática conviene mencionar las obras que Mendoza Garrido ha dedicado al tema de la delincuencia en el Campo de Calatrava $(87,88,89)$; así como la reciente aportación de López Gómez acerca de la conflictividad urbana en esta clase de espacios (84).

9. Rodríguez-PicaVea Matilla, Enrique: Formación del feudalismo en la Meseta meridional castellana: los señoríos de la Orden de Calatrava en los siglos XII-XIII. Madrid, Siglo XXI, 1994. 
La vida económica y el fisco en tierras de la orden es otro de los puntos en los que debemos detenernos a lo largo de estas líneas, ya que la explotación de sus dominios patrimoniales y jurisdiccionales le generaba cuantiosos y variados beneficios procedentes de las rentas. Lamentablemente, hoy en día, la bibliografía de que disponemos para aproximarnos a estas cuestiones no es muy pródiga. De hecho, solo hemos encontrado dos investigaciones que sigan esta línea para el caso que nos ocupa: la de Baury, que se adentra en la dimensión fiscal de Calatrava (36); y la de Santos Carrascosa, para los bienes de la mesa maestral de Zorita (I27). También han sido varios los estudios que han abordado la materia de una manera más general; nos referimos a los artículos de Peinado Santaella (IOI), Ladero Quesada (78), Porras Arboledas (IO2) y Sánchez Quiñones (I26).

\subsection{ORGANIZACIÓN INSTITUCIONAL Y DISTRIBUCIÓN DEL PODER}

Tras habernos detenido en el gobierno y la administración de los señoríos de Calatrava, es el momento de abordar la cuestión de su funcionamiento institucional y la distribución del poder dentro de ella en las dos últimas centurias medievales; ya que estos organismos conocieron una acentuada jerarquización en su interior, reflejo del reparto del poder político, económico y eclesiástico. En este sentido observamos que, pese al enorme interés que para la historiografía tiene el tema que nos ocupa, han sido muy pocos los autores que han estudiado de manera conjunta estos aspectos en lo concerniente a nuestra protagonista. Solo Villegas Díaz ha realizado publicaciones de este tipo en un intento por recomponer su organización interna, de un lado, y las transformaciones que experimentó entre los últimos años del siglo XIV y la primera mitad del XV, de otro (I56, I57).

No obstante, si bien es cierto que las obras generales que tratan la temática son muy escasas, la situación cambia radicalmente cuando dirigimos nuestra mirada hacia el maestre y sus correspondientes soportes económico-institucionales, los maestrazgos; debido a que han sido muchos los interesados en ampliar sus conocimientos sobre esta figura y sus sólidas bases materiales. Así ocurre, por ejemplo, con Carlos de Ayala, que se ha adentrado en estas cuestiones para el ámbito de la Corona de Castilla (28); con Ladero Quesada, que ha hecho lo propio con las mesas maestrales de Calatrava y Santiago (78); y con O'Callaghan y Díaz Martín, que han centrado su atención en la actitud que mostraron las milicias y sus representantes ante la guerra civil castellana $(99,59)$.

El maestre Pedro Girón es el que mayor curiosidad ha suscitado de todos cuantos ostentaron la máxima dignidad de la orden y las prolijas publicaciones sobre el mismo así lo evidencian. Aquí se enmarcarían las de Viña Brito (I58, I59), Cabrera (4I), Val Valdivieso (15I) y O' Callaghan (97). Por el contrario, su hijo Rodrigo Téllez Girón no ha disfrutado de la misma popularidad y solo Torres Suárez 
y Ciudad Ruiz han presentado una síntesis de los años en los que estuvo al frente de la entidad cisterciense (I50, 52). De otro lado, la historia de Gonzalo Núñez de Guzmán y Enrique de Villena la han cubierto las aportaciones de Casado Quintanilla y Riera i Sans, respectivamente (49, 50, I04); mientras que hacia Martín López de Córdoba se han orientado las de Molina Molina y Díaz Martín $(94,58)$.

Volviendo al tema del maestrazgo, resulta lógico que los freires, cada vez más aristocratizados, no vieran con buenos ojos el progresivo incremento de la autoridad maestral y se opusieran, en más de una ocasión, a esta nueva situación, que iba en detrimento del protagonismo de los órganos corporativos y del propio capítulo general. Así, en el tiempo en que las reformas se acababan de producir y no estaban todavía consolidadas se sucedieron varias reacciones ante estos sistemas de gobierno en el seno de la Orden de Calatrava; que actualmente nos resultan muy cercanas gracias a los trabajos de Rodríguez-Picavea (II9) y Cabrera (40, 42, 43).

A diferencia de lo que sucedía en los casos anteriores, el estudio de las restantes dignidades laicas y eclesiásticas que conformaban estos organismos, constituye un porcentaje mínimo de la bibliografía relacionada con la materia, a causa de la escasa popularidad que viene rodeando al tema desde un principio. Por ende, este tipo de investigaciones son alarmantemente escasas; especialmente en lo que afecta a los priores y sacristanes, sobre los que no se ha escrito nada por el momento. Ligeramente mejor es la situación en la que se encuentra el comendador dentro de la producción historiográfica; pues actualmente disponemos de una aportación que se ha internado en el conocimiento de estos delegados del poder maestral en los territorios sobre los que tenían jurisdicción: la de López Casas (82). A esta se suma el artículo que Ostos Salcedo ha editado en torno a Enrique de Figueredo, un personaje que estuvo estrechamente vinculado a don Pedro Girón y que pudo haber ostentado el cargo de canciller (IOo).

En última instancia, y a pesar de no estar relacionados directamente con la temática, conviene citar ante su conexión con Fernán Gómez de Guzmán, los esfuerzos que Cabrera, García Aguilera y Hernández Ossorno han dedicado a la sublevación que estalló en el concejo de Fuenteovejuna en el año I476 y que culminó con el brutal asesinato de este comendador (39, 45, 46, 65).

\subsection{FUNCIONES Y ACTIVIDADES DE LOS FREIRES CALATRAVOS}

El estudio de las funciones desarrolladas por Calatrava entre I350 y 1500 es fundamental de cara a obtener una imagen completa de su evolución histórica y de las razones que propiciaron su transformación a lo largo de la Edad Media. Por todo ello resulta muy llamativa la poca frecuencia con que se ha abordado la actividad militar de las órdenes (a pesar de ser la principal), así como que no se haya compuesto todavía una obra de carácter monográfico sobre ella. A eso hay 
que añadir que, a día de hoy, las pocas investigaciones que se han llevado a cabo en relación con este campo han consistido en una mera descripción del papel que los freires jugaron en los distintos conflictos armados que tuvieron por escenario la Península Ibérica ${ }^{\mathrm{Io}}$. Consecuentemente, son todavía muchos los progresos que han de realizarse dentro de la presente línea de conocimiento.

Observamos que dichas investigaciones son especialmente parcas a la hora de tratar la participación de la entidad en la guerra contra otros hermanos de fe. De hecho, solo el profesor Carlos de Ayala se ha internado en estas cuestiones para el periodo cronológico que nos atañe, y más concretamente, durante las famosas guerras civiles castellanas (30). Algo más abundante es, sin embargo, el número de publicaciones de que disponemos para conocer el grado de efectividad que estos instrumentos de la Cristiandad y de la propia monarquía alcanzaron en las zonas fronterizas con al-Ándalus. De un lado, están aquellas que nos ofrecen una visión completa acerca de la presencia que tuvieron en estos cambiantes espacios a lo largo de los siglos XIII y XIV, como la de Josserand (74) y la del ya mencionado Carlos de Ayala (33); mientras que, de otro, están las que inciden en sectores específicos de las extremaduras, como sucede con la de López Fernández (83) Suárez Fernández (I35) y Rodríguez Picavea (I20). Este último medievalista se ha preocupado, igualmente, por las fortalezas calatravas y su valor en la organización territorial y socioeconómica del reino de Castilla, en general y del Campo de Calatrava, en particular (II2). Esto mismo han hecho Molero García y Segovia Fernández (92, 93, I28).

Tampoco la dimensión espiritual y religiosa de los freires (y no digamos ya la hospitalaria) escapa al problema anterior; y es que esta no ha sido una de las áreas de atención preferente para los historiadores hasta hace poco más de una década. La devoción constituye, en definitiva, uno de los grandes temas olvidados en el estudio de las milicias hispánicas, y particularmente en lo que al Bajo Medievo se refiere. La excepción a esta norma la conforman los valiosísimos estudios que la profesora Torres Jiménez nos ha ofrecido sobre distintos aspectos de la materia a lo largo de su trayectoria como investigadora (I38 a I48).

\subsection{CALATRAVA Y SU RELACIÓN CON LOS RESTANTES PODERES POLÍTICOS Y ECLESIÁSTICOS}

La bibliografía de que disponemos para conocer los lazos existentes entre la Orden de Calatrava y las restantes autoridades políticas y eclesiásticas del reino es cuantiosa pero claramente desigual. Esto es debido a que los especialistas han concedido un mayor protagonismo al estudio de su vinculación con los poderes

10. Ayala Martínez, Carlos de: «Balance y actualidad de la historiografía...», p. 112. 
laicos, mientras que los eclesiásticos han sido relegados a un segundo plano. Por consiguiente, la naturaleza de sus contactos con la monarquía se ha venido investigando desde hace ya muchos años; de modo que las obras que tratan estos aspectos son relativamente numerosas (aunque ninguna de ellas profundiza en el caso calatravo de manera particular).

Quien mejor ha detallado dicho proceso ha sido el profesor Carlos de Ayala, que se ha adentrado en las reformas que los reyes acometieron sobre estos organismos peninsulares para ejercer un mayor control de sus estructuras políticas y económicas $(25,32)$. Pero también Díaz Martín, Mitre Fernández, Javierre Mur y Val Valdivieso han progresado en esta línea y lo han hecho mediante el análisis de las intrusivas políticas que Pedro I y la dinastía Trastámara aplicaron en este sentido (59, 90, 70, I5I).

Dentro de este campo se hallan, además, las prolijas investigaciones que han visto la luz acerca de la proximidad entre Calatrava y los contextos nobiliarios a fines del Medievo; que deben su autoría principalmente a Rodríguez-Picavea (2I, 68, II3 a II8, I22, I57). En esta ocasión, la tendencia historiográfica que observábamos antes vuelve a repetirse, aunque de manera algo más tardía.

La situación empieza a cambiar, sin embargo, cuando fijamos nuestra atención en el carácter de sus relaciones con los concejos (tanto de realengo como de su propia jurisdicción); ya que todavía hoy siguen siendo insuficientes las obras de conjunto sobre la materia (9I, I05, I34). Aquí cabe resaltar las concretas e interesantes publicaciones de Fernández Izquierdo (64), Ciudad Ruiz (54), Rodríguez-Picavea (I08), Buitrago Oliver (37) y Villegas Díaz (I52 a I54).

Finalmente, solo nos resta reseñar dentro del presente apartado el escaso protagonismo que se ha concedido tradicionalmente a las posturas mantenidas por las autoridades eclesiásticas ante las milicias asentadas en la Península Ibérica, en general y los hermanos calatravos, en particular. Las excepciones a esta constante las constituyen las aportaciones de Díaz Ibáñez (57), Torija Fernández (I37) y Raquel Torres (I48).

\subsection{FUENTES Y DOCUMENTOS EDITADOS}

Antes de cerrar este repaso historiográfico consideramos oportuno detenernos en un proceso de gran trascendencia para el estudio de nuestra protagonista: la edición de fuentes. Y es que dicho proceso, junto a la composición de guías y regestas, agiliza enormemente la tarea del investigador; dado que los datos más relevantes sobre esta institución son los que se derivan del análisis de la documentación procedente de sus archivos, conservados en su mayoría en la Sección de Órdenes Militares del Archivo Histórico Nacional de Madrid. Concretamente sobre esta sección se han preparado algunos índices con la intención de facilitar el acceso a sus fondos (7, 18, I9). 
Generalmente, los especialistas suelen optar por la publicación de fuentes que atañen a una única entidad; aunque en ocasiones pueden estar ligadas a varias de ellas, como sucede con la Crónica de Rades y Andrada (I6) o con la Historia de las órdenes militares de Santiago, Calatrava y Alcántara desde su fundación hasta el Rey don Felipe Segundo de Caro de Torres (4). En el caso calatravo, esta tendencia de la que hablamos ha tenido una notable relevancia dentro de su estudio y la edición de repertorios documentales ha sido reiterada. Así lo evidencian, por ejemplo, las distintas Definiciones de la Orden de Calatrava que J. F. O'Callaghan ha puesto a nuestra disposición (I2 a I4), el estudio diplomático de Casado Quintanilla de los documentos expedidos por la milicia en la segunda mitad del siglo XV (5) y la edición facsímil del Bullarium Ordinis Militae de Calatrava (I5).

Tampoco escapa a todo este proceso la documentación concejil de sus señoríos, gracias a la publicación parcial de los fondos de algunos archivos municipales, como el de Manzanares (3), Maqueda (Io) y Cogolludo (8, 9). Dentro de esta línea se sitúan, igualmente, los índices y catálogos que se han compuesto para los archivos de Almoguera (I), Almonacid de Zorita (6, I7) y Ciudad Real (2).

\section{CONSIDERACIONES FINALES: VACÍOS INFORMATIVOS Y NUEVAS LÍNEAS DE ESTUDIO}

Nuestro objetivo a lo largo de las páginas precedentes ha sido realizar un «estado de la cuestión», que reúna las obras más importantes que se han redactado sobre la Orden de Calatrava en la Castilla bajomedieval; para poder obtener una visión general de los progresos alcanzados hasta nuestros días y de aquellos campos que han merecido una menor atención por parte de los medievalistas.

Llegados a este punto, hay que advertir que tanto la producción bibliográfica como el volumen de fuentes que han sido editadas en torno a esta entidad son abundantes, pero ciertamente desiguales. Son sustancialmente más numerosos los documentos de que disponemos para conocer el siglo $\mathrm{XV}$, mientras que aquellos que hacen alusión a la centuria inmediatamente anterior son claramente más escasos. Por consiguiente, resultan mayores los conocimientos que la historiografía posee en torno a los freires calatravos en las décadas finales del periodo medieval. De igual forma ocurre con los distintos aspectos políticos, institucionales, económicos, organizativos y religiosos que los rodean.

En cualquier caso, de la lectura de las páginas que integran el presente artículo se desprende una conclusión evidente: a pesar del interés que los expertos han mostrado por estos organismos, el tema dista de estar agotado y nuestros conocimientos de ser completos; ya que aún hoy en día perviven problemas que dificultan su comprensión. De hecho, todavía continúan girando numerosos interrogantes en torno a ellos, lo que favorece la apertura de novedosas líneas de estudio y la publicación de nuevas monografías. Así lo evidencian el volumen 
sobre élites y órdenes aparecido en 2015 (76) y el de órdenes y construcción de la sociedad occidental en 2016 (I49).

Por todo ello, se van a proponer a continuación varias líneas de trabajo vinculadas a Calatrava en su etapa bajomedieval, que en la actualidad no han recibido la atención necesaria o que, simplemente, permanecen en un plano secundario. Retos de futuro que, a nuestro juicio, son imprescindibles de cara a obtener un conocimiento completo sobre la materia. Estas, no obstante, pueden extrapolarse también, en mayor o menor medida, a las restantes instituciones religioso-guerreras.

La primera asignatura pendiente de la historiografía sería la redacción de obras de síntesis que recojan el desarrollo institucional de esta entidad en la Edad Media; o, al menos, bajo el gobierno de la dinastía Trastámara. Y es que, aunque en el transcurso de las dos últimas décadas han sido varios los especialistas que se han atrevido a redactar libros de carácter general, que aglutinan a la totalidad de las milicias nacidas en suelo peninsular; aún no se han realizado los mismos esfuerzos para el caso del que ahora nos ocupamos. Por lo tanto, son alarmantemente minoritarios (además de antiguos) los estudios de estas características que existen hoy en día.

Este mismo problema afecta también a otros dos campos. En primer lugar, a los estudios comparativos; una nueva tendencia dentro de la investigación que apenas hoy recibe atención, pero que poco a poco empieza a cobrar algo de fuerza entre los medievalistas más jóvenes y que puede aportar datos ciertamente interesantes y novedosos. Y es que la comparación (particularmente la geográfica) es esencial a la hora de reconstruir la Historia porque nos permite hallar similitudes, e incluso patrones, en la evolución de los distintos espacios y grupos humanos; así como reforzar hipótesis anteriores.

En segundo término, se encontrarían los análisis prosopográficos, que favorecen la obtención de un conocimiento más profundo de los miembros que conformaban las órdenes militares. Hablamos de una labor imprescindible de cara a entender los lazos que se entablaron entre los distintos sectores de la aristocracia y estos organismos; dado que la creciente intromisión nobiliaria en ellas no fue una tendencia generalizada desde el mismo momento en que surgieron. Por ende, solo a través de una lectura detallada y minuciosa de las trayectorias biográficas de los personajes que ocuparon sus más altas dignidades, es posible comprender la verdadera magnitud de este fenómeno ${ }^{\text {II }}$. Sin embargo, no resulta sencillo que los especialistas se animen a adentrarse en una tarea tan necesaria como plagada de dificultades; pues han de hacer frente, por un lado, a la discontinuidad o simplemente ausencia de la documentación y, por el otro, a la existencia de numerosos fondos que aún están por revisar ${ }^{12}$. (Precisamente este es uno de los retos asumidos

11. Ayala Martínez, Carlos de: «Balance y actualidad de la historiografía de Órdenes Militares en los reinos medievales de León y Castilla (2004-2014)». Cuadernos de Cehimo, 41 (2014), p. 115.

12. No obstante, contamos con algunos precedentes dentro de este campo. Por ejemplo, la Universidad Autónoma 
por el equipo investigador de Historia Medieval de la Universidad de Castilla-La Mancha en el marco de su proyecto nacional en curso $^{\mathrm{I3}}$.)

El gobierno y la administración de los señoríos calatravos en la mitad norte de la Península Ibérica es otra de las tareas pendientes a las que queremos hacer mención; puesto que apenas se tienen datos de la presencia de esta institución en la zona entre I350 y I500. También alrededor de la vida económica y las rentas de sus dominios giran algunos interrogantes que no han podido ser resueltos por el momento. Nos referimos concretamente a la polémica que se generó allá por la década de 1970 en torno a la estructuración de las rentas feudales, como consecuencia del replanteamiento crítico que Jesús Martínez Moro hizo de las delimitaciones jurídicas establecidas por Salvador Moxó. Fue precisamente este autor quien replanteó desde una perspectiva innovadora el tema de su clasificación; llegando a la conclusión de que no existe un único sistema que encasille absolutamente todos los conceptos en virtud de los cuales los señores reclamaban sus pagos y que un excesivo formalismo jurídico puede deformar la visión de conjunto de estas rentas ${ }^{14}$.

Pero no han sido estas las únicas ramas de la investigación que no han recibido la atención necesaria por parte de la historiografía. Tampoco la dimensión interna y los aspectos sociológicos de Calatrava durante los siglos XIV y XV, así como el papel que la mujer ocupaba en esta entidad han sido una de las áreas de preocupación dominante en estos años; de modo que estas siguen componiendo líneas de estudio abiertas y a la espera de nuevos planteamientos.

La situación cambia radicalmente cuando dirigimos nuestra mirada hacia el funcionamiento institucional y la distribución del poder dentro de la milicia; porque los especialistas suelen mostrar un interés especial por los miembros de las grandes familias nobiliarias, encargados de la gestión de sus recursos y de sus políticas. Consecuentemente, en las últimas décadas los maestres y sus soportes económico-institucionales (los maestrazgos) han disfrutado de un notable protagonismo dentro de la historiografía. En contraposición, y aquí radica la dificultad, el estudio de las restantes dignidades, tanto laicas como eclesiásticas, constituyen un porcentaje mínimo de la bibliografía relacionada con la materia, a causa de la escasa popularidad que viene rodeando al tema desde un principio. Por ende, las obras que han salido a la luz sobre comendadores mayores y demás cargos y

\footnotetext{
de Madrid desarrolló un ambicioso proyecto financiado por la Fundación San Benito de Alcántara (2006-2009), con el que pretendía realizar un análisis prosopográfico de las dignidades de Calatrava y Alcántara entre los siglos XII y XV. Este llevaba por título: Relaciones sociales y de poder en la Castilla medieval. Prosopografía de las órdenes militares de Calatrava y Alcántara (siglos XII-XV). Desgraciadamente sus resultados no han sido publicados en su totalidad a día de hoy. 13. Actualmente, el Ministerio de Economía y Competitividad está financiando un proyecto de investigación de la Universidad de Castilla-La Mancha, que está dirigido por el profesor Francisco Ruiz Gómez y que lleva por título: Órdenes militares y construcción de la sociedad occidental: cultura, religiosidad, género y desarrollo social en los espacios de frontera (siglos XII-XV).

14. Martínez Moro, Jesús: La renta feudal en las Castilla del siglo XV: los Stúñiga. Valladolid, 1977.
} 
oficios son infinitamente más reducidas que aquellas sobre las figuras maestrales; especialmente en lo que afecta a los priores.

Este mismo problema atañe igualmente al campo de las relaciones que se entablaron con los restantes poderes políticos y eclesiásticos castellanos; debido a que tradicionalmente se ha concedido una mayor atención a su vinculación con las autoridades laicas, mientras que las eclesiásticas han sido relegadas a un segundo plano. Específicamente la naturaleza de los contactos que se establecieron con la monarquía, la nobleza y los órganos concejiles en el transcurso de la Baja Edad Media, se ha venido investigando desde hace ya muchos años y no ha dejado de hacerse. Sin embargo, han sido pocos los autores que se han esforzado por descubrir las posturas adoptadas por los poderes eclesiásticos ante ellas.

Tampoco las funciones y actividades militares, religiosas y hospitalarias en las que se empleaban los freires entre 1350 y I500 gozan de peso en la bibliografía; aunque dichas obligaciones resultan fundamentales de cara a obtener una imagen completa de su evolución histórica y de las razones que propiciaron su transformación a lo largo de la Edad Media. La participación calatrava en los diferentes conflictos armados que tuvieron lugar en estos años ${ }^{15}$ y su dimensión religiosa y eclesiástica (no digamos ya la hospitalaria) han sido algunos de los grandes temas olvidados en el estudio de las órdenes peninsulares; ya que no han logrado despertar la curiosidad de los historiadores hasta hace aproximadamente una década. Por todo ello, los progresos alcanzados en este sentido son leves y las incógnitas muy numerosas.

Llegados a este punto, solo nos resta hacer mención a dos últimas líneas de trabajo pendientes de atención. De un lado, la que tiene que ver tanto con la edición de fuentes documentales, como con la de índices y regestas que faciliten su conocimiento y un mejor acceso a los archivos históricos. No vamos a negar, ni mucho menos, que los avances que se han producido hasta el momento son loables y que esta tendencia ha gozado de un relativo protagonismo desde hace ya algún tiempo dentro del estudio de las milicias hispánicas. Sin embargo, no está de más recordar que dichas ediciones solo son coyunturales y que la realización de esta tarea de forma sistemática no se ha intentado todavía para Calatrava. Recapitulando, contamos en la actualidad con una cantidad nada desdeñable de documentos generados por estos organismos, por lo que la necesidad de intensificar y sistematizar su proceso de publicación es toda una realidad de nuestro tiempo.

De otro lado, el análisis de las crónicas bajomedievales es igualmente obligatorio si se quiere alcanzar una imagen realmente completa de la temática. En esta ocasión, puede que sea el precario desarrollo historiográfico o simplemente la falta de interés el motivo que explica la escasa atención que los medievalistas

15. Lamentablemente, este reto de futuro resultará especialmente difícil de superar para la historiografía española, a causa de la parquedad documental y el reducido número de datos de que disponemos. 
han concedido al papel de estas instituciones dentro de la cronística y a la imagen que de ellas se proyectaba. Únicamente sabemos de la existencia de dos trabajos que profundicen en la materia de manera general: los que el profesor Philippe Josserand elaboró en 2002 y 2003 respectivamente ${ }^{\mathrm{I} 6}(73,75)$.

Para concluir, solo nos gustaría advertir que, aunque nuestra intención a lo largo del presente artículo ha sido realizar una revisión, lo más exhaustiva posible, del estado en el que se hallan las investigaciones sobre Calatrava a fines del Medievo, esta se encuentra lejos de ser definitiva y las conclusiones formuladas quedan abiertas a ulteriores revisiones, como ocurre siempre en los estudios históricos, y más con los de carácter recopilatorio.

16. A ambos trabajos conviene añadir el del profesor Carlos Barquero Goñi, de carácter algo más concreto: Barquero Goñı, Carlos.: «La Orden de San Juan en Castilla según la cronística medieval (siglos XII-XIV)». Actas del Primer Simposio Histórico de la Orden de San Juan en España. (Madrid y Consuegra, 1990). 2003, pp. 57-63. 


\section{RELACIÓN DE FUENTES EDITADAS}

I. Ballesteros San José, P. y González Manteca, O.: «Almoguera. Catálogo de los documentos medievales en su archivo municipal», Wad-al-Hayara, 8 (I98I), pp. 227-245.

2. Canorea Huete, J.: «El Archivo General de Calatrava y la documentación conservada en el Histórico Provincial de Ciudad Real» en IzQuierdo Benito, R. y Ruız Gómez, F. (coord.): Las Órdenes Militares en la Edad Media. Volumen I. Cuenca, Universidad de Castilla-La Mancha, 2000, pp. 95-I09.

3. CAÑIgal CoRTÉs, L.: Documentos inéditos para la Historia de Manzanares. Ciudad Real, I982.

4. Caro de Torres, F.: Historia de las órdenes militares de Santiago, Calatrava y Alcántara desde su fundación hasta el Rey don Felipe Segundo, Administrador perpetuo dellas. madrid, I629.

5. Casado Quintanilla, B.: Corona de Castilla: documentos de la Orden de Calatrava expedidos durante los tres últimos maestrazgos (I445-I489). Estudio diplomático. Madrid, I997.

6. Fernández Izquierdo, F., Santos Carrascosa, M.T. y Yuste Martínez, M.A.: «Catálogo del Archivo Municipal de Almonacid de Zorita (Guadalajara), siglos XIII-XIX», Wad-al-Hayara, 8 (I98I), pp. 85-2I4.

7. Javierre Mur, A. Y G. del Arroyo, C.: Guía de la Sección de las órdenes militares. Archivo Histórico Nacional. Patronato Nacional de Archivos Históricos. Madrid, s.f.

8. López Gutiérrez, A.J.: «Documentación señorial y concejil de Cogolludo en el Archivo Ducal de Medinaceli (II76-I530)», Historia, Instituciones, Documentos, Io (I983), pp. 157-250.

9. López Gutiérrez, A.J.: Documentación del señorío de Cogolludo en el Archivo Ducal de Medinaceli de Sevilla (II76-I530). Zaragoza, I989.

io. Malalana Ureña, A.: «Las ordenanzas de Maqueda (I399)», Anuario de Historia del Derecho Español, 57 (1987), pp. 617-632.

II. MARAÑón. M: Libro del origen, definiciones y actas capitulares de la Orden de la ínclita Cavalleria de Calatrava. Valladolid, Adrián Ghemart, 1568.

I2. O'CALlaGHan, J.F.: «Difiniciones of the Order of Calatrava enacted by Abbot William Il of Morimond, April 2, I468». Traditio, I4 (I958), pp. 23I-268.

I3. O'Callaghan, J.F.: «Difiniciones of the Order of Calatrava, I304-I383». Tradition, I7 (I96I), pp. 255-284.

I4. O'CALlaghan, J.F.: «Las definiciones de la Orden de Calatrava, I383-I4I8» en La España Medieval, I9 (I996), pp. 99-I24.

I5. Ortega y Cotes, I.J., Álvarez de Baquedano, J.F., Oriega Zúñiga y Aranda, P.: Bullarium Ordinis Militae de Calatrava, per annorum seriem nonnullis, donationum, concordiarium et aliis interfectis scripturis congestum. Barcelona, I98I.

I6. RADES y ANDRADA, F. de: Chronica de las tres ordenes y Cavallerias de Sanctiago, Calatrava y Alcantara. Toledo, I572, ed. facsimilar, Valladolid, 2009.

I7. Riesco Terrero, A.: «Colección sigilográfica del Archivo de Almonacid de Zorita: los sellos maestrales y los concejiles de Zorita y Almonacid», Wad-al-Hayara, 8 (I98I), pp. 215-226.

I8. Romero Fernández Pacheco, J.R.: «Archivos y documentos medievales de las Órdenes Militares en el Archivo Histórico Nacional» en Torres Jıménez, R. y Ruız Gómez, F. (coord.): Órdenes militares y construcción de la sociedad occidental. Cultura, religiosidady desarrollo social de los espacios de frontera (siglos XII-XV). Madrid, Sílex, 20I6, pp. 3I-78.

I9. Uhagón, F. de: Índice de los documentos de la Orden Militar de Calatrava existentes en el Archivo Histórico Nacional. B.R.A.H., XXXV (I899), pp. 5-I67. 


\section{RELACIÓN BIBLIOGRÁFICA}

20. Agostinı Banús, E.: Historia de Almodóvar del Campo. Ciudad Real, i99o (red. facsímil). 2I. Arcaz Pozo, A.: «Nobleza y órdenes militares en la Galicia bajomedieval» en Medievalismo: Boletín de la Sociedad de Estudios Medievales, 5 (1995), pp. I27-I50.

22. Arcaz Pozo, A.: «La tenencia de fortalezas nobiliarias en Galicia y su proyección en los dominios de las órdenes militares durante la Baja Edad Media» en BARrio BARrio, J.A. y Cabezuelo Pliego, J.V.: La fortaleza medieval: realidad y símbolo. I998, pp. 243-256.

23. Ayala Martínez, C. de; Rodríguez-Picavea Matilla, E. y otros: «Las Órdenes Militares en la Edad Media peninsular: Historiografía I976-1992. Reinos de Castilla y León». Medievalismo: Boletín de la Sociedad Española de Estudios Medievales, 2 (I992), pp. II9I69 у 3 (I993), pp. 87-I44.

24. Ayala Martínez, C. de: «San Felices de Amaya, monasterio medieval de la Orden de Calatrava» en Medioevo Hispano. Estudios en memoria del profesor Derek W. Lomax. Madrid, I995, pp. I7-34.

25. Ayala Martínez, C. de: «La Corona de Castilla y la incorporación de los maestrazgos» en Militarium Ordinum Analecta, I (I997), pp. 257-290.

26. Ayala Martínez, C. de: «Las órdenes militares y los procesos de afirmación monárquica en Castilla y Portugal (I250-I350)» en As relaçoes de froteira no século de Alcanices. IV Jornadas Luso-Espanholas de História Medieval. Actas, vol. II, Porto, I998, pp. I279-I3I2.

27. Ayala Martínez, C. de: «Un cuestionario sobre una conspiración. La crisis del maestrazgo de Calatrava en I3II-I3I3» en Aragón en la Edad Media, XIV-XV. Homenaje a la profesora Carmen Orcástegui Gros. Zaragoza, I999, pp. 73-89.

28. Ayala Martínez, C. de: «Maestres y maestrazgos en la Corona de Castilla (siglos XIIXV)» en IzQuierdo Benito, R. y Ruiz Gómez, F. (eds.): Las Órdenes Militares en la Edad Media. Volumen I. Cuenca, Universidad de Castilla-La Mancha, 200o, pp. 325-378.

29. Ayala Martínez, C. de: «Las órdenes militares en la Corona de Castilla en el siglo XIV» en Martínez Hernando, Y. y Casa Martínez, C. de la: Monografías universitarias. El siglo XIV: El alba de una Nueva Era. Soria, Universidad Internacional Alfonso VIII, 200I, pp. I93-203.

30. Ayala Martínez, C. de: «Las Órdenes Militares ante la guerra civil castellana (I366-I37I)» en Poder y sociedad en la Baja Edad Media Hispánica. Estudio en homenaje al profesor Luis Vicente Díaz Martín. Universidad de Valladolid, 2002, I, pp. 37-58.

3i. Ayala Martínez, C. de y Barquero GoÑI, C.: «Historiografía hispánica y Órdenes Militares en la Edad Media, I993-2003». Medievalismo: Boletín de la Sociedad Española de Estudios Medievales, I2 (2003), pp. IOI-I62.

32. Ayala Martínez, C. de: «La incorporación de los maestrazgos» en Ribot, L., Valdeón, J. y MAzA, E. (eds.): Isabel la Católica y su época. Actas del Congreso Internacional 2004. Valladolid, 2007, I, pp. 285-297.

33. Ayala Martínez, C. de: «Presencia y protagonismo de las Órdenes Militares castellanoleonesas en la frontera (s. XIII-XIV)» en Rodríguez de la PeÑA, M.A. (dir.): Hacedores de frontera. Estudios sobre el contexto social de la Frontera en la España medieval. Madrid, 2009, pp. I6I-I78.

34. Ayala Martínez, C. de: «Balance y actualidad de la historiografía de Órdenes Militares en los reinos medievales de León y Castilla (2004-20I4)». Cuadernos de Cehimo, 4I (20I4), pp. I05-I4I. 
35. Ballesteros SAN-José, P: Señoríos entre el Tajo y el Tajuña durante la Baja Edad Media. Evolusion histórica de los alfoces de Zorita y Almoguera (siglos XI-XV). (Memoria de licenciatura inédita, leída en la Universidad Complutense de Madrid), I982.

36. BAURY, G.: «Les ordres militaires hispaniques et l'économie cistercienne. Le temporel des soeurs de Calatrava (XIII -XVe siècles)», e-Spania [en red], I6 (2013).

37. Buitrago Oliver, J.C.: «Ciudad Real y Calatrava en el siglo XV: una pluralidad conflictiva». Montesinos, 7-8 (1988), pp. 20-25.

38. Burdeus, M.D.: «La traducción al servicio de la Orden de Calatrava», en, Burdeus, M.D., ReAL, E. y Verdelga, J.M. (eds.): Las Órdenes Militares: realidad e imaginario, Castellón, Universidad Jaime I, 2000, pp. 223-242.

39. CABrera, E.: «La sublevación de Fuenteovejuna de i476: revisión del problema» en Andalucía Medieval: nuevos estudios. Córdoba, I979, pp. I47-I74.

40. CABRERA, E.: «En torno a una enconada rivalidad por el maestrazgo de Calatrava durante el siglo XV» en Espacio, tiempo y forma. Serie III. Historia Medieval. Homenaje al profesor don Eloy Benito Ruano, I (I988), pp. 75-96.

4I. CABrera, E.: «De Osuna a Fuenteovejuna. La transformación en señorío de una antigua encomienda mayor de Calatrava» en Osuna en tiempos medievales y modernos (siglos XIII-XVIII). Sevilla, I995, pp. 53-62.

42. CABRERA, E.: «El acceso a la dignidad de maestre y las divisiones internas de las Órdenes Militares durante el siglo XV» en IzQuierdo Benito, R. y Ruiz Gómez, F. (coord.): Las Órdenes Militares en la Edad Media. Volumen I. Cuenca, Universidad de Castilla-La Mancha, 2000, pp. 28I-306.

43. CABRera, E.: «El maestrazgo de Calatrava, objeto de disputa entre los Guzmán y los Girón durante el siglo XV» en IzQuierdo Benito, R. y Ruiz Gómez, F. (eds.): Actas del Congreso, Tierra del Quijote. Tierra de Órdenes Militares. Junta de Comunidades de Castilla-La Mancha y Fundación Quijote, IV Centenario, Ciudad Real, 2007, pp. 7-30.

44. CABRERA, E.: «Sobre los señoríos de las órdenes militares en el reino de Castilla» en ID: Feudalismo y señoríos al sur del Tajo (siglos XIII al XV). Córdoba, Publicaciones obra Social y Cultura Cajasur, 2007, pp. I5-35.

45. CABRERA, E. y otros: «La sublevación de Fuenteovejuna, contemplada en su V centenario» en Actas del II Congreso de Historia de Andalucía. Andalucía medieval, II, Córdoba, I978, pp. II3-I22.

46. CABRERA, E. y Moros, A.: Fuenteovejuna. La violencia antiseñorial en el siglo XV. Barcelona, I99I.

47. Caro de Torres, F.: Historia de las órdenes militares de Santiago, Calatrava y Alcántara, desde su fundación hasta el rey don Felipe II, Administrador Perpetuo de ellas. Madrid, I629.

48. CASAdo Quintanilla, B.: «La cancillería y las escribanías de la Orden de Calatrava», Anuario de Estudios Medievales, I4 (1984), pp. 73-99.

49. CASAdo Quintanilla, B.: «Gonzalo Núñez de Guzmán, maestre de Alcántara y Calatrava, al servicio de la Corona de Castilla y León» en Espacio, Tiempo y Forma. Serie III. Historia Medieval, 25 (2012), pp. I47-I72.

50. Casado Quintanilla, B.: «Años de cambio en Calatrava. El maestrazgo de Gonzalo Núñez de Guzmán (I385-I404)» en TORRes JimÉnez, R. y Ruiz Gómez, F. (coord.): Órdenes militares y construcción de la sociedad occidental. Cultura, religiosidady desarrollo social de los espacios de frontera (siglos XII-XV). Madrid, Sílex, 20I6, pp. 377-427.

5I. CASAs del Río, A.: «Puertollano en el marco de la Orden de Calatrava» en VI Semana de Historia de Puertollano. Ciudad Real, I986, pp. II-44.

52. Ciudad Ruiz, M.: «El maestrazgo de don Rodrigo Téllez Girón». En la España Medieval, 23 (2000), pp. 3I2-365. 
53. Ciudad Ruiz, M.: El dominio señorial y eclesiástico de la Orden de Calatrava. Ciudad Real, Ediciones C\&G, 2008.

54. Ciudad Ruiz, M.: «Almagro y la Orden de Calatrava a través de los libros de visitas. Siglo XV». Revista de las Ordenes Militares, 6 (2010), pp. 45-88.

55. Corchado Soriano, M.: Estudio histórico-económico-jurídico del Campo de Calatrava. 3 vols. Ciudad Real, I982-I984.

56. CORRAL VAL, L.: «Las relaciones institucionales entre las órdenes de Calatrava y Alcántara (siglos XII-XV)». Revista de las Órdenes Militares, 5 (2009), pp. 77-Io6.

57. DíAz lвáÑEz, J.: «Las órdenes militares y la iglesia de Cuenca durante la Edad Media» en Izquierdo Benito, R. y Ruiz Gómez, F. (eds.): Las Órdenes Militares en la Edad Media. Volumen I. Cuenca, Universidad de Castilla-La Mancha, 2000, pp. I049-Io70.

58. Díaz Martín, L.V.: «La elección de Martín López de Córdoba como maestre de Calatrava» en Studia Silensia, I. Homenaje a fray Justo Pérez de Urbel, OSB, I, Abadía de Silos, I976, pp. 423-432.

59. Díaz Martín, L.V.: «Los maestres de las órdenes militares en el reinado de Pedro I de Castilla» en Hispania, XL (I980), pp. 285-356.

6o. Estow, C.: The Order of Calatrava, its development and its role in the castilian crisis of the mind-fourtheenth century. Brandeis University, I975.

6r. Estow, C.: «The economic development of the Order of Calatrava, II58-I366» en Speculum, 57 (1982), pp. 267-291.

62. FERnÁndez IzQUierdo, F.: La encomienda calatrava de Vállaga, siglos XV-XVIII. Su explotación económica y la administración de sus rentas. Madrid, I985.

63. Fernández IzQuierdo, F.: «Órdenes militares y régimen señorial. Los dominios de Calatrava en tierras de la provincia de Guadalajara (siglos XI-XIV) en Wad-Al-Hayara, I2 (I985), pp. 69-79.

64. FERNÁNDEZ IZQUIERDO, F.: «El régimen concejil de Almonacid de Zorita bajo el dominio de la Orden de Calatrava (siglos XIII-XVI). Anuario de Estudios Medievales, I6 (I986), pp. 39I-420.

65. García Aguilera, R. y Hernández Ossorno, M.: Revuelta y litigios de los villanos de la encomienda de Fuenteovejuna (I476), Madrid, I975.

66. García-Velasco Martín de Almagro, S.: Historia de Daimiel. Madrid, 1987.

67. GonZÁlez, H.: «Influjo de la Orden Militar de Calatrava en la Reconquista española, II58-I487» en Cistercium, 59 (I958), pp. 315-323.

68. GonZÁlez SÁnchez, S.: «La presencia de la media y baja nobleza en las Órdenes Militares durante la minoría de Juan II de Castilla» en Revista de las Órdenes Militares, 7 (2013), pp. 57-70.

69. Herrera Casado, A.: Historia de Almonacid de Zorita. Almonacid de Zorita, I990.

70. Javierre MUR, A. «Fernando el Católico y las Órdenes Militares españolas» en Fernando el Católico. Vida y obra. V Congreso de Historia de la Corona de Aragón. Estudios, I, Zaragoza, I955, 285-300.

7I. Josserand, P.: «L' historiographie des Ordres Militaires dans les royaumes de Castille et de León. Bilan et perspectives de la recherche en histoire médiévale». Atalaya. Revue française d'études médiévales hispaniques, París, 9 (1998), pp. 5-44.

72. Josserand, P.: «Les Ordres Militaires et le service curial dans le royaume de Castille (I252-1369)» en Leroy, B. (ed.): Les serviteurs de l'Etat au Moyen Âge. Actes du XXIX congrès de la SHMESP. París, I999, pp. 75-83. 
73. JosSERAND, P.: «Enjeux de pouvoir et traitement historiographique: les ordres militaires dans la chronique royale castillane aux XIII e et XIV e siècles» en Cahiers de linguistique et de civilisation hispaniques médiévales. 25 (2002), pp. I83-I93.

74. Josserand, P.: «Un corps d'armée spécialise au service de la Reconquète. Les Ordres Militaires dans le royaume de Castille (1252-1369)» en Bulletin de la Société Archéologique et Historique de Nantes et de Loire-Atlantique. Nantes, I37 (2002), pp. I93-2I4.

75. JOSSERAND, P.: «Les ordres militaires dans la chronique castillane à l'époque de Rodrigo Jiménez de Rada», en Cahiers de linguistique et de civilisation hispaniques médiévales, 26 (2003), pp. I23-I32.

76. Josserand, P.: Église et pouvoir dans la Péninsule Ibérique. Les Ordres Militaires dans le royaume de Castille (I252-I369). Madrid, Casa de Velázquez, 2004.

77. Josserand, P.H.; Oliveira, L. y Carraz, D. (eds.): Élites et ordres militaires au moyen âge. Rencontre auour D'Alain Demurger. Madrid, Casa de Velázquez, 2015.

78. Ladero Quesada, M.A.: «Algunos datos para la historia económica de las Órdenes Militares de Santiago y Calatrava en el siglo XV». Hispania, 30-II6 (I97I), pp. 637-662.

79. Ladero Quesada, M.A.: «Comentarios sobre los señoríos de las Órdenes Militares de Santiago y Calatrava en Castilla La Nueva y Extremadura a fines de la época medieval» en Las Órdenes Militares en el Mediterráneo Occidental (siglos XIII-XVIII). Casa de Velázquez-Instituto de Estudios Manchegos, I989, pp. I69-I80.

8o.LAdero Quesada, M.A.: «La investigación sobre Órdenes Militares en la Edad Media hispánica durante los últimos decenios: Corona de Castilla y León» en IzQUIERDo BENITO, Ricardo y Ruız Gómez, Francisco (coords.): Las Órdenes Militares en la Edad Media. Volumen I. Cuenca, Universidad de Castilla-La Mancha, 2000, pp. 9-3I.

8I. Lomax, D.: «Las Órdenes Militares en la Península Ibérica durante la Edad Media» en Repertorio de historia de las ciencias eclesiásticas en España, 6, Salamanca, I976.

82. López CASAS, M.: «Fernán Gómez de Guzmán: el envés histórico de la figura del comendador de Fuenteovejuna» en Real Ramos, E., Verdegal Cerezo, J.M. y Burdeus Pérez, M.D. (coord.): Las Órdenes Militares: realidad e imaginario. Servicio de publicaciones Universitat Jaume I, 2000, pp. 469-480.

83. López Fernández, M.: «Las órdenes religioso-militares en la frontera de Tarifa (I273I388)» en Al Qandir: Monografías y documentos sobre la historia de Tarifa, I2 (2012), pp. 54-65.

84. López Gómez, O.: «Conflictividad urbana y estrategias de pacificación en la Castilla bajomedieval. Las tierras de las Órdenes Militares» en Torres JıMÉnEz, R. y Ruız Gómez, F. (coord.): Órdenes militares y construcción de la sociedad occidental. Cultura, religiosidad y desarrollo social de los espacios de frontera (siglos XII-XV). Madrid, Sílex, 20I6, pp. 5II-538.

85. Maldonado Cocat, R.J.: Almagro, cabeza de la Orden y Campo de Calatrava. Madrid, I979.

86. Menache, S.: «La Orden de Calatrava y el clero andaluz (siglos XIII-XV)». En la España Medieval, V. Estudios en memoria del profesor D. Claudio Sánchez-Albornoz, I. Madrid, I986, pp. 633-653.

87. Mendoza Garrido, J. M.: Violencia, delincuencia y persecución en el Campo de Calatrava a fines de la Edad Media. Ciudad Real, I995.

88. Mendoza Garrido, J. M.: Delincuencia y represión en la Castilla bajomedieval: los territorios castellano-manchegos. Granada, I999.

89. Mendoza Garrido, J. M.: «Los fuegos en el Campo de Calatrava a fines de la Edad Media» en IzQuierdo Benito, R. y Ruiz Gómez, F. (eds.): Las Órdenes Militares en la Edad Media. Volumen I. Cuenca, Universidad de Castilla-La Mancha, 2000, pp. 837-859. 
9O.Mitre FernÁNDEZ, E.: «Los maestres de las Órdenes Militares castellanas y la «revolución» Trastámara» en IzQuierdo Benito, R. y Ruiz Gómez, F. (eds.): Las Órdenes Militares en la Edad Media. Volumen I. Cuenca, Universidad de Castilla-La Mancha, 2000, pp. 259-280. 9i. MolÉnAT, J. P.: «Les tolédans dans les ordres militaires du XIle au XVe siècle» en Fernandes I. C. F. (ed.): As Ordens Militares e as Ordens de Cavalaria na Constrçao do Mundo Occidental. Actas do IV Encontro sobre Ordens Militares. Lisboa-Palmela, 2005, pp. 26I-277.

92. Molero García, J.M.: «El binomio castillo-casa de la encomienda en la administración señorial de la Orden de Calatrava (siglos XII-XV)» en FERREIRA, I.C.: Castelos das Ordens Militares. 2014, pp. 229-249.

93. Molero García, J.M.: Castillos y fortalezas medievales del Campo de Calatrava (siglos IX-XVI). Ciudad Real, Instituto de Estudios Manchegos, 2017.

94. Molina Molina, A.L.: «Martín López de Córdoba, maestre de Alcántara y Calatrava y adelantada mayor de Murcia» en Anuario de Estudios Medievales, II (I98I), pp. 749-758.

95. Mondéjar Soto, M: Breve historia de Puertollano. Puertollano, I977.

96. Mondéjar Soto, M: Miguelturra. Historia y tradición. Puertollano, I978.

97. O' Callaghan, J. F.: «Don Pedro Girón, master of the Order of Calatrava, I445-I466», en Hispania, 2I (1961), pp. 342-392.

98. O'CALlAGHAN, Joseph: The Spanish Military Order of Calatrava and its Affiliates, Londres, Variorum, I975.

99. O' Callaghan, J. F.: «The Masters of Calatrava and the Castilian Civil War, I350-I369» en Die Geistlichen Ritterorden Europas. Sigmaringen, I980, pp. 353-374.

ioo. Ostos Salcedo, P.: «Enrique de Figueredo, ¿Canciller de la Orden de Calatrava?, Historia, Instituciones, Documentos, 3I (2004), pp. 45I-474.

IoI. Peinado Santaella, R.G.: «La renta señorial en las Órdenes Militares de la Corona de Castilla durante la Baja Edad Media» Historia, Instituciones, Documentos, I8 (I99I), pp. 403-424.

I02. Porras ArboledAs, P.A.: «La hacienda de las órdenes militares en la Baja Edad Media castellana» en Estudio en homenaje a don Claudio Sánchez Albornoz en sus noventa años. Anexos de C.H.E., 4 (ig86), pp. 535-555.

I03. Ramírez de Arellano, R.: «Rebelión de Fuenteovejuna contra el Comendador Mayor de Calatrava, Fernán Gómez de Guzmán, I476» en B.R.A.H., 39 (I90I), pp. 446-5I2.

IO4. Riera i SANS, J.: «Enric de Villena, maestre de Calatrava» en Estudios históricos y documentales de los Archivos de Protocolos, 7 (I979), pp. I09-I32.

I05. Rodríguez Blanco, D.: «Los concejos de las órdenes militares en la Baja Edad Media. Organización y relaciones de poder» en Historia, Instituciones, Documentos, I8 (I99I), pp. 425-443.

io6. Rodríguez Molina, J.: «Las órdenes militares de Calatrava y Santiago en el Alto Guadalquivir (siglos XIII-XV)» en Cuaderno de Estudio Medievales, 2-3 (I975).

I07. Rodríguez-Picavea Matilla, E.: «Catorce años de historiografía sobre la Orden de Calatrava en la Edad Media (I976-I989)» en Hispania, 50, I75 (I990), pp. 94I-964.

io8. Rodríguez-Picavea Matilla, E.: «Aproximación a la geografía eclesiástica del arcedianato de Calatrava (siglos XII-XVI)». Hispania Sacra, XLIII (I99I), pp. 735-773.

iog. Rodríguez-Picavea Matilla, E.: «Génesis y evolución del señorío calatravo en Alcaudete (siglos XIII-XV)» en Primeras Jornadas sobre Alcaudete y su historia. Alcaudete, I994, pp. I57-I79. 
ito. Rodríguez-Picavea Matilla, E.: La villa y la tierra de Maqueda en la Edad Media. Evolución de un concejo toledano desde el realengo hasta el final del señorío calatravo (siglos XI-XV). Toledo, I996.

iII.Rodríguez-Picavea Matilla, E.: «La villa y la encomienda de Calatrava la Vieja en la Baja Edad Media». Espacio, tiempo y forma. Serie III. Historia Medieval, I2 (I999), pp. I39-I8I.

II2. Rodríguez-Picavea Matilla, E.: «Fortalezas y organización territorial en el Campo de Calatrava (siglos XII-XV)» en FernANDES, I. (ed.): Mil anos de fortificaçoes na Peninsula Iberica e no Magreb (500-I500): Actas do Simpósio Internacional sobre castelos. LisboaPalmela, 2002, pp. 623-632.

iI3.Rodríguez-Picavea Matilla, E.: «La nobleza y la Orden de Calatrava en tiempos de Juan Il de Castilla» en As Ordens Militares e de Cavalaria na Construçao do Mundo Ocidental. Actas do IV Encontro sobre Ordens Militares. Lisboa, 2005, pp. 585-620.

iI4. Rodríguez-Picavea Matilla, E.: «Prosopografía de la Orden de Calatrava en Castilla. La primera mitad del siglo XV» en Meridies. Revista de Historia Medieval, VII (2005), pp. $201-244$.

II5. Rodríguez-Picavea Matilla, E.: «Linaje y poder en la Castilla Trastámara. El ejemplo de la Orden de Calatrava» en Anuario de Estudios Medievales, 35 (2005), pp. 9I-I30.

ii6. Rodríguez-Picavea Matilla, E.: «Caballería y nobleza en la Orden de Calatrava: Castilla, I350-I450» en Anuario de Estudios Medievales, 37 (2007), pp. 7II-740.

iI7. Rodríguez-Picavea Matilla, E.: «El proceso de aristocratización de la Orden de Calatrava (siglos XIII-XV)» en Hispania Sacra, LIX (2007), pp. 493-535.

iI8. Rodríguez-Picavea Matilla, E.: «Caballeros calatravos y linajes castellanos (mediados del siglo XIV-mediados del siglo XV)» en Fernandes I.C.F. (ed.): As Ordens Militares e as Ordens de Cavalaria entre o Occidente e o Oriente. Actas do V Encontro sobre Ordens Militares. Palmela, 2009, pp. I57-I86.

iI9. Rodríguez-Picavea Matilla, E.: «Maestres versus caballeros. La disidencia frente al poder en la orden de Calatrava (siglos XII-XV)» en Nuevos Mundos, Mundos Nuevos, junio (2009), ed. electrónica.

I2O. Rodríguez-Picavea Matilla, E.: «The Military Orders and the war of Granada (I350I492)». Mediterranean Studies, I9 (2010), pp. 2I-4I.

I2I. Rodríguez-Picavea Matilla, E.: «The Military Orders in Medieval Iberia. Image, propaganda and legitimacy». Mirator, I3 (2012), pp. I-35.

I22. Rodríguez-Picavea Matilla, E. y Pérez Monzón, O.: «Mentalidad, cultura y representación del poder de la nobleza calatrava en la Castilla del siglo XV» en Hispania, 66 (2006), pp. 199-242.

I23. Ruiz Gómez, F.: Los orígenes de las órdenes militares y larepoblación de los territorios de La Mancha (II5O-I250). Madrid, Consejo Superior de Investigaciones Científicas, 2003.

I24. SÁnchez Domingo, R.: Las monjas de la orden militar de Calatrava. Monasterio de San Felices (Burgos) y de la Concepción (Moralzarzal-Madrid). Burgos: La Olmeda, I997.

I25. SÁnchez Lillo, J.: «Puertollano en la Alta y Baja Edad Media» en VII, VIII y IX Semanas de Historia de Puertollano (celebradas en I986, I987 y I988), Ciudad Real, I989, pp. 75-94.

I26. SÁnchez QuiÑones, J.: «La pesca en los territorios castellanos de las Órdenes Militares de Santiago y de Calatrava (I450-I550): Organización del espacio y técnicas pesqueras» en Torres Jiménez, R. y Ruiz Gómez, F. (coord.): Órdenes militares y construcción de la sociedad occidental. Cultura, religiosidad y desarrollo social de los espacios de frontera (siglos XII-XV). Madrid, Sílex, 20I6, pp. 539-564. 
I27. Santos Carrascosa, M.T.: Estudios de los bienes de la mesa maestral de Zorita en los siglos XV Y XVI a través de una fuente documental: Las Visitas. (Memoria de Licenciatura inédita, leída en la Universidad Complutense de Madrid), I983.

I28. Segovia Fernández, A. M.: «Sacro Convento y Castillo de Calatrava la Nueva (Aldea del Rey, Ciudad Real)» en Investigaciones arqueológicas en Castilla la Mancha (I9962002), Toledo, 2004, pp. 449-46r.

I29. Segura Graíño, C. y Torreblanca, A.: «Las órdenes militares en el reino de Córdoba en la Baja Edad Media» en Andalucía entre Oriente y Occidente (I236-I492). Actas del V Coloquio Internacional de Historia Medieval de Andalucía. Córdoba, I988, pp. I23-I34.

I30. Solano Ruiz, E.: «El señorío de la Orden de Calatrava en Andalucía al término de la Edad Media». Cuadernos de Historia. Anexos de la Revista Hispania, 7 (I977), pp. 97-I65.

I3I.Solano Ruiz, E.: La Orden de Calatrava en el siglo XV. Los señoríos castellanos de la orden al fin de la Edad Media. Sevilla, 1978.

I32. Solano Ruiz, E.: «El convento de San Salvador de Pinilla a fines de la Edad Media. Aportación para su estudio». Revista de Historia Canaria, 38 (I984-I986), pp. 533-553.

I33. Solano Ruiz, E.: «Una fortaleza de la Orden de Calatrava en Andalucía: Porcuna a fines de la Edad Media» en Homenaje a Juan Torres Fontes, II. Murcia, I987, pp. I619-I635.

I34. Solano Ruiz, E.: «El control de la gestión concejil en el señorío castellano de la Orden de Calatrava a fines de la Edad Media» en Sarasa, E. y Serrano, E. (eds.): Señorío y feudalismo en la Península Ibérica. Zaragoza, I993, I, pp. 615-629.

I35. SuÁrez Fernández, L.: «Las Órdenes Militares y la guerra de Granada». Sevilla, Fundación Sevillana de Electricidad, I992, pp. 4-30.

I36. Toomaspoeg, K.: «Les ordres militaires au service des pouvoirs monarchiques occidentaux» en Josserand, P.H.; Oliveira, L. y CARraz, D. (eds.): Élites et ordres militaires au moyen âge. Rencontre auour D'Alain Demurger. Madrid, Casa de Velázquez, 2015, pp. 32I-332.

I37. Torija Rodríguez, E.: «Las Órdenes Militares y el arzobispado de Toledo en la Baja Edad Media. Estructuración de la geografía diocesana en las zonas de frontera controladas por las Órdenes Militares y en el adelantamiento de Cazorla» en ToRrES JimÉnez, R. y Ruız Gómez, F. (coord.): Órdenes militares y construcción de la sociedad occidental. Cultura, religiosidad y desarrollo social de los espacios de frontera (siglos XII$X V)$. Madrid, Sílex, 20I6, pp. 607-642.

I38. TORRES JimÉnez, R.: Religiosidad popular en el Campo de Calatrava: cofradía y hospitales al final de la Edad Media. Ciudad Real, Instituto de Estudios Manchegos, I989.

I39. TORRES JIMÉNEZ, R.: «Liturgia y espiritualidad en las parroquias calatravas (siglos XVXVI)» en IzQuierdo R. y Ruiz F. (eds.): Las órdenes militares en la Península Ibérica, I: Edad Media. Cuenca, Universidad de Castilla-La Mancha, 2000, pp. Io87-III6.

I40. Torres Jiménez, R.: «Devoción eucarística en el Campo de Calatrava al final de la Edad Media. Consagración y elevación» en Memoria Ecclesiae, XX (2002), Religiosidad popular y archivos de la Iglesia, 293-328.

I4I. Torres Jiménez, R.: Formas de organización y práctica religiosa en Castilla la Nueva, siglos XIII-XVI. Madrid, Universidad Complutense de Madrid, 2002.

I42. TORRES JimÉNEZ, R.: «Religiosidad laica en tierras calatravas: cofradías de Valdepeñas al final de la Edad Media» en Iglesia y religiosidad en España. Historia y archivos. Guadalajara, 2002, pp. 653-677.

I43. TORRES JimÉnEz, R.: «Pecado, confesión, sociedad bajo dominio calatravo al final del Medievo» en Os reinos ibéricos na Idade Média: livro de homenagem ao professor doutor Humberto Carlos Baquero Moreno. Vol. I. 2003, pp. I267-I274. 
I44. TORRES JIMÉNEZ, R.: «La influencia devocional de la Orden de Calatrava en la religiosidad de su señorío durante la Baja Edad Media». Revista de Órdenes Militares, 3 (2005), pp. 37-75.

I45. TORRES JimÉNEZ, R.: «Bibliotecas de parroquias rurales y religiosidad popular en Castilla al final de la Edad Media» en Boucheron, P. y Ruiz Gómez, F.: Modelos culturales y normas sociales al final de la Edad Media. 2009, pp. 429-484.

I46. TORRES JimÉnEz, R.: «La Iglesia y el territorio. Las órdenes militares y su proyección eclesiástica y religiosa» en López Villaverde, A.L. (coord.): Historia de la Iglesia en Castilla-La Mancha. Ciudad Real, Ediciones de Castilla-La Mancha, 2oro, pp. 35-49.

I47. TORRES JimÉnEZ, R.: «El clero rural asalariado y la Orden Militar de Calatrava al final de la Edad Media» en Mundos Medievales: espacios, sociedades y poder. Homenaje al profesor José Ángel García Cortázar y Ruiz de Aguirre. Vol. 2. 2012, pp. I949-I962.

I48. Torres JimÉNeZ, R.: «Clérigos parroquiales en tierra de Órdenes Militares al final del siglo XV» en Torres Jiménez, R. y Ruiz Gómez, F. (coord.): Órdenes militares y construcción de la sociedad occidental. Cultura, religiosidad y desarrollo social de los espacios de frontera (siglos XII-XV). Madrid, Sílex, 20I6, pp. 565-606.

I49. Torres JimÉnez, R. y Ruiz Gómez, F. (coord.): Órdenes militares y construcción de la sociedad occidental. Cultura, religiosidad y desarrollo social de los espacios de frontera (siglos XII-XV). Madrid, Sílex, 20 I6.

I50. Torres SuÁrez, C.: «Don Rodrigo Téllez Girón, Maestre de Calatrava». Miscelánea Medieval Murciana, III (I977), pp. 4I-7I y Anuario de Estudios Medievales, II (I98I), pp. 775-792.

I5I. Val Valdivieso, M.I.: «Relaciones de Don Pedro Girón, maestre de Calatrava, con el rey Don Enrique IV» en VII Centenario del Infante don Fernando de la Cerda. Ciudad Real, I976, pp. I59-I70.

I52. Villegas DíAZ, L. R.: «Algunos datos acerca de las luchas entre la Orden de Calatrava y el concejo de Villa Real en la primera mitad del siglo XIV» en VII Centenario del Infante don Fernando de la Cerda. Madrid, I976, pp. I79-I9o.

I53. Villegas DíAz, L. R.: Ciudad Real en la Edad Media. La ciudad y sus hombres (I255-I500). Ciudad Real, I98I.

I54. Villegas DíAz, L. R.: «Calatrava y Ciudad Real. Unas notas sobre las relaciones de la ciudad y la Orden (siglos XIII-XV)». Cuadernos de Estudios Medievales, VIII-IX (I983), pp. 215-240.

I55. Villegas DíAz, L. R.: «Almagro durante la Edad Media (aproximación)» en I Semana de Historia de Almagro. Ciudad Real, I986, pp. 35-47.

I56. Villegas Díaz, L. R.: «La Orden de Calatrava. Organización y vida interna» en Primeras Jornadas de Historia de las Órdenes Militares. Madrid, I996, pp. 29-5I.

157. Villegas DíAz, L.R.: «Las transformaciones de la Orden de Calatrava a fines del siglo XV» en La Península Ibérica en la era de los descubrimientos, I39I-I492. Actas de las III Jornadas Hispano-Portuguesas de Historia Medieval. Sevilla, I997, pp. 689-705.

I58. Viña Brito, A.: «El testamento de Don Pedro Girón». Anuario de Estudios Medievales, I9 (I989), pp. 493-505.

I59. Viña BRITO, A.: «Don Pedro Girón y los orígenes del Señorío de Osuna». Historia, Instituciones y Documentos, I7 (I990), pp. 267-285.

I6o. VV. AA.: Historia de la provincia de Ciudad Real. Ciudad Real, I986.

I6I. VV. AA.: La provincia de Ciudad Real-II. Historia. Ciudad Real, I992.

I62. YÁÑEz, M.D.: «Calatrava: el retoño del Císter (II58-I958)» en Hidalguía, 6 (I958), pp. 727-748. 
Calidad de Revistas

científicas Españolas

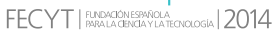

SERIE III HISTORIA MEDIEVAL

REVISTA DE LA FACULTAD DE GEOGRAFÍA E HISTORIA
AÑO 2018

ISSN: 0214-9745

E-ISSN 2340-1362

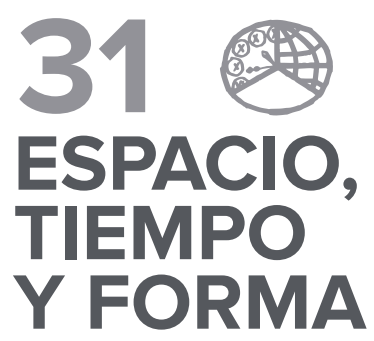

GREGoRIO DEL SER QUIJANO

Carmelo Luis López, In Memoriam

\section{Artículos · Articles}

29 Soha ABBoud Haggar

Un resumen del tratado jurídico de Al-Tafrí: el Manuscrito Árabe 1233 del Monasterio de El Escorial y su supuesta relación con Leyes de Moros

EDUARDo Aznar VALLejo

Norma y conflicto en la navegación castellana bajomedieval

69 Carlos Barquero Goñ

Transferencias de recursos de la Orden de San Juan desde España hasta el Mediterráneo Oriental durante la Edad Media

\section{Margarita Cabrera Sánchez}

La muerte del príncipe Don Juan. Exequias y duelo en Córdoba y Sevilla durante el otoño de 1497

\section{Francisco de Paula Cañas Gálvez}

Primogenitura, continuidad dinástica y legitimitad instituciona en Castilla a principios del siglo XV: Catalina de Trastámara, Princesa de Asturias (1422-†1424)

\section{Paloma Cuenca Muñoz}

El códice visigótico de los Moralia in lob, ms. lat. 83 de la John Rylands Library de Manchester

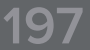

\section{JOSÉ MARÍA DIAGO JIMÉNEZ}

Las instituciones educativas de carácter religioso en el reino hispanovisigodo de los siglos VI y VII a través de los cánones conciliares y las reglas monásticas

MARÍA Díez Yáñez

La Ética aristotélica en Castilla: las bibliotecas universitarias medievales y prerrenacentistas

\section{Estefanía Ferrer del Río}

Rodrigo de Mendoza, I Marqués del Cenete y I Conde del Cid: paralelismos entre su biografía y su pretendida genealogía

\section{ALEJANDRo García Morilla \\ Escritura publicitaria de transición: entre la visigótica y la carolina.} El paradigma burgalés

María Dolores García Oliva

Señores contra campesinos: un conflicto por la tierra en Mirabel a finales de la Edad Media y principios de los Tiempos Modernos (1488-c. 1520)
34.3 jaime García Carpintero lópez de Mota

La hospitalidad santiaguista a finales de la Edad Media: el proyecto de reconstrucción del hospital de Alarcón

377 LAURA DA GRACIA

La posesión agraria individual en los registros notariales de Fuente el Sol (1481-1482

4.03 Mauricio Herrero Jiménez

El valor de los documentos reales en los procesos de la Real Chancillería de Valladolid

4.31 Miguel José López-Guadalupe Pallarés

Procesos de señorialización en los concejos de la Extremadura castellano-leonesa. Un estado de la cuestión

455 Ángel Martínez Catalán

Las rentas decimales del cabildo catedralicio de Cuenca a inicios del siglo XV (1400-1432)

4.83 Gonzalo Oliva Manso

Cien años de moneda en Castilla (1172-1268). El siglo del maravedí de oro

521 jesús Olivet García-Dorado

El cabildo de curas y beneficiados de Toledo en la segunda mitad del siglo XV. Composición y aspectos institucionales (1455-1488)

547 Mariel PÉrez

Clérigos rurales, comunidades y formación de las estructuras parroquiales en la diócesis de León (siglos XI-XIII)

575 Milagros Plaza Pedroche

La Orden de Calatrava en la Baja Edad Media (1350-1500): repaso historiográfico

597 Pedro Andrés Porras Arboledas

La pervivencia del Fuero de Cuenca en los inicios de la Modernidad: el testimonio de los fueros de Consuegra y Requena

619 Juan Pablo Rubio Sadia

Los mozárabes frente al rito romano: balance historiográfico de una relación polémica

SANDRA SUÁREZ GARCíA

Los habices de la Vega de Granada como forma de conocimiento del reino nazarí y su transformación tras la conquista: la alquería de La Zubia 


\section{1}

\section{ESPACIO,}

\section{TIEMPO}

\section{Y FORMA}

SERIE III HISTORIA MEDIEVAL

REVISTA DE LA FACULTAD DE GEOGRAFÍA E HISTORIA

\section{De medievalistas ilustres · On Renowned Medievalists}

671 Francisco Abad Nebot

Entradas para un Diccionario

\section{Libros $\cdot$ Books}

679 Almagro Vidal, Clara, Paisajes medievales en el Campo de Calatrava (CARLos BARQUero GoÑI)

681 Carvajal Castro, Álvaro, Bajo la máscara del Regnum. La monarquía asturleonesa en León (854-1037) (JOSÉ MANUEL RODRÍGUEZ GARCíA)

683 Fuente Pérez, María Jesús, Violante de Aragón, reina de Castilla (ANa EcheVArRía Arsuaga)

687 Martín Prieto, Pablo, Historia del pensamiento medieval: filosofia y teología (FRANCISCO LEÓN FLORIDO)

689 Pardo de Guevara y Valdés, Eduardo (ed.), Mujeres con poder en la Galiciamedieval (siglos XIII-XV). Estudios, biografías y documentos (ENRIQUE CANTERA MONTENEGRO)

693 Ríos Saloma, Martín (ed.), El mundo de los conquistadores (Jessica Ramírez MéndeZ)

690 Solórzano Telechea, Jesús, Arízaga Bolumburu, Beatriz y BOCHACA, Michel (eds.), Las sociedades portuarias de la Europa atlántica en la Edad Media (ANTONIO ORTEGA VILLOSLADA)

703 VAL VALDIVIEso, María Isabel del (coord.), El agua en el
imaginario medieval. Los reinos ibéricos en la Baja Edad Media (MARÍA Jesús Fuente)

707 Villar García, Luis Miguel, Archivo Municipal de Segovia. Documentación medieval, 1166-1474 (ENRIQUE CANTERA MONTENEGRO) 